\title{
Citrate inhibition of cisplatin reaction with DNA studied by fluorescently labeled oligonucleotides: implication for selectivity towards guanine
}

\author{
Feng Wanga, Po-Jung Jimmy Huang a and Juewen Liu ${ }^{\text {a,* }}$
}

${ }_{5}$ Received 18th July 2013, Accepted 16th August 2013
DOI: 10.1039/c3cc45458d

The reaction between cisplatin and DNA is conveniently studied using fluorescently labeled oligonucleotides and gel electrophoresis; as an example of application, the inhibition

10 of this reaction by citrate is demonstrated, which might increase selectivity of cisplatin towards guanine over adenine.

Cisplatin is one of the most successful and important anticancer drugs. ${ }^{1-4}$ It is generally accepted that DNA is the molecular target of cisplatin, forming intrastrand crosslinked ${ }_{15}$ guanines, ${ }^{1}$ although the exact mechanism is still under debate. ${ }^{5}$ A lot has already been learned about the reaction between DNA and cisplatin. ${ }^{6}$ The difference in the $\mathrm{Cl}^{-}$ concentration outside a cell $(\sim 100 \mathrm{mM})$ and inside ( 4-12 $\mathrm{mM}$ ) might facilitate dissociation of $\mathrm{Cl}^{-}$and adding water 20 inside the cell. ${ }^{1}$ The aquated product is trapped in the cell to react with various nucleophilic species including DNA., Mechanisms related to electron transfer have also been proposed. ${ }^{9}$ Due to the lack of appropriate analytical tools to follow cisplatin inside live cells, ${ }^{5}$ most studies were carried 25 out in simple buffers. The cellular environment, however, is much more complex containing numerous small molecules, nucleic acids and proteins that compete for cisplatin binding. ${ }^{10,11}$ The cisplatin concentration inside cells is estimated to be just nanomolar to low micromolar. ${ }^{5}$ Many 30 cellular compounds can tightly bind to cisplatin, leaving little free cisplatin for DNA binding. Examples of such competitors include sulfer containing proteins, ${ }^{12,13}$ glutathione (GSH), ${ }^{14,15}$ and even inorganic anions. ${ }^{16}$ Before cisplatin can react with DNA, it has to be released from these competing ligands. ${ }^{17}$

35 Many inorganic ions have a high cellular concentration and may affect cisplatin binding to DNA. For example, phosphate, acetate, and carbonate have been shown to bind to cisplatin. ${ }^{16,18-21}$ Citrate is an important cellular metabolite but its effect on cisplatin has not been studied. Cellular citrate 40 concentration is high in Aspergillus niger $(\sim 2-30 \mathrm{mM}),{ }^{22}$ and in Saccharomyces cerevisiae $(\sim 3 \mathrm{mM}) .{ }^{23,24}$ In human tissues, citrate was reported to be $0.2-0.45 \mathrm{mM} .^{25}$ This is likely to be under-estimated since most citrate resides in mitochondria, where it is formed and utilized to make lipids. ${ }^{26}$ It has also 45 been suggested that the real target of cisplatin might be the mitochondria DNA instead of the nuclear DNA, ${ }^{27}$ where the role of citrate is even more relevant. Therefore, we are interested in studying the effect of citrate on the reaction between cisplatin and DNA.

50 Cisplatin binding to DNA has been monitored using HPLC $,{ }^{28,29} \mathrm{NMR},{ }^{30}$ electrochemistry, ${ }^{31}$ mass spectrometry, ${ }^{32}$ and elemental analysis. ${ }^{33}$ Compared to these methods, gel electrophoresis is more cost-effective and readily accessible to many researchers. It can tolerate complex sample matrix 55 without worrying about clotting of column or spectroscopic interference. Gel electrophoresis has been used to confirm DNA binding by cisplatin in a few reports, ${ }^{16,28,34}$ where most employed radioisotope labels or DNA staining dyes for imaging long biolgical DNA. Given the development and 60 recent applications of covalent fluorophore labels, such advances have not been widely applied to study DNA/cisplatin reaction. ${ }^{35}$ Herein, we use gel electrophoresis to follow this reaction in citrate buffer.

FAM (carboxyfluorescein)-labeled DNAs are popular ${ }_{65}$ probes because of their low cost and high quantum yield. As an initial test, we employed FAM-labeled 15-mer DNA homopolymers. The DNAs were mixed with increasing concentrations of cisplain for $16 \mathrm{~h}$ and the samples were then loaded into a non-denaturing polyacrylamide gel. A gradual 70 shift of the FAM-A 15 band with reduced mobility was observed with increasing cisplatin concentration (Figure 1A), suggesting reaction between this DNA and cisplatin. The PtDNA adduct did not migrate as a single band, suggesting the presence of a broad range of products, possibly due to 75 different levels and positions of platination. Fluorescence quenching was also observed, especially at high $\mathrm{Pt}$ concentrations. On the other hand, no shift was observed with FAM-T 15 and its fluorescence just dropped in intensity with increasing cisplatin concentration (Figure 1B). Reactions also 80 occurred with FAM- $\mathrm{C}_{15}$ and its product distribution pattern was quite different, where discrete bands were observed at low $\mathrm{Pt}$ concentrations and the gel smeared at high $\mathrm{Pt}$ concentrations (Figure 1C). Finally, FAM-G 15 showed slightly smeared gel even for the initial free DNA, possibly due to its 85 tendency to form various secondary structures such as interand intra-molecular quadruplexes (Figure 1D). Mass spectrum of FAM-G ${ }_{15}$ showed a few high molecular weight species, consistent with the smeared gel (Figure S1, ESI). Addition of cisplatin produced a clear shift, consistent with the fact that 
cisplatin has high affinity toward guanine.

This initial test suggests that FAM-labeled DNA and gel electrophoresis can be used to study DNA reaction with cisplatin but fluorescence quenching needs to be suppressed. ${ }_{5}$ We next tested Alexa Fluor 647 (AF) labeled $\mathrm{T}_{15}$, since AF is known to be a more stable fluorophore. We chose $\mathrm{T}_{15}$ for its low reactivity with cisplatin and fluorescence intensity can be directly compared. Using a short incubation time of $2 \mathrm{~h}, \sim 20 \%$ qenching was observed with FAM, while AF was not 10 significantly quenched (Figure 2A). It needs to be noted that longer incubation can also quench $\mathrm{AF}$, but to a less extent than FAM quenching. Therefore, we chose to use AF-labeled DNA for subsequent studies.

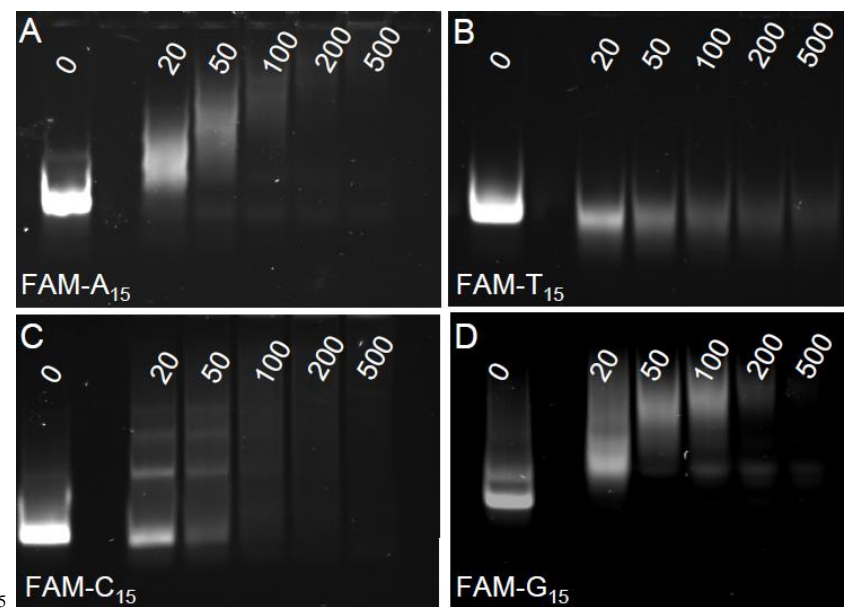

Figure 1. Gel images of FAM-labeled $A_{15}(A), T_{15}(B), C_{15}(C)$ and $G_{15}(D)$ after reacting with various concentrations of cisplatin in water. The DNA concentrations are $0.5 \mu \mathrm{M}$ and the numbers marked on each lane are the molar ratio between cisplatin and DNA.

20 First, the cisplatin concentration-dependent study was repeated, where $\mathrm{AF}-\mathrm{A}_{15}$ still showed a similar mobility shift but the overall fluorescence intensity was stronger (Figure $2 \mathrm{~B})$. On the other hand, no reaction took place with $\mathrm{AF}_{-} \mathrm{T}_{15}$ as expected and the band intensity was quite consistent (Figure ${ }_{25} 2 \mathrm{C}$ ). Next a time-dependent study was performed with AF$\mathrm{A}_{15}$. It is clear that the bands shifted to lower mobility over time (Figure 2D). We quantified the relative mobility shift by measuring the center of each band and obtained a reaction rate of $0.36 \mathrm{~h}^{-1}$ between cisplatin and AF-A 15 (Figure S2). This 30 rate is comparable with the literature reports. ${ }^{16}$

After optimizing the assay conditions, we next studied the reaction in citrate buffers using AF-A 15 . First, $0.25 \mathrm{mM}$ cisplatin was mixed with various concentrations of citrate for $24 \mathrm{~h}$ to allow complex formation. Then AF-A 15 was added and 35 incubated for another $16 \mathrm{~h}$. In Figure 2E, the first lane on the left is the free DNA without cisplatin. All the other lanes contained cisplatin and the citrate concentration was gradually decreased. We observed a gradual mobility shift, which can be pictured as an inhibition curve and the middle point is $\sim 0.5$ $40 \mathrm{mM}$ citrate. Since the Pt concentration was $0.25 \mathrm{mM}$, the inhibition effect by citrate is close to quantitative. Strong free DNA bands were observed with $5 \mathrm{mM}$ citrate, where no cisplatin/DNA adduct was detected. Since cisplatin binding to DNA is thermodynamically stronger than to most other
${ }_{45}$ ligands, ${ }^{17}$ inhibit was incomplete at low citrate concentrations. After reacting with citrate, negatively charged complexes are formed, which might be a kinetic reason to disfavor the reaction with negatively charged DNA.
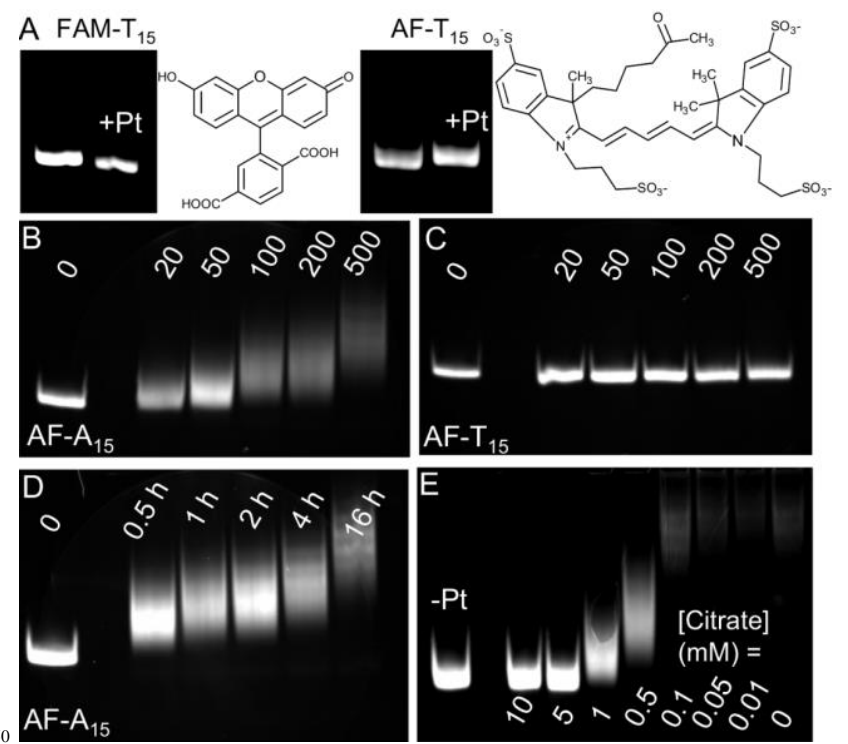

Figure 2. (A) Gel images of FAM and AF-labeled $T_{15}$ and after cisplatin treatment for $2 \mathrm{~h}$. The structures of these two fluorophores are also shown. Gel images of $\mathrm{AF}-\mathrm{A}_{15}(\mathrm{~B})$, and $\mathrm{AF}^{-\mathrm{T}_{15}}$ (C) after reacting with various concentrations of cisplatin. The DNA concentrations are $0.5 \mu \mathrm{M}$ and the 55 numbers marked on each lane are the molar ratio between cisplatin and DNA. (D) Gel images of AF- $\mathrm{A}_{15}$ after incubating with cisplatin for various time. Cisplatin concentration $=250 \mu \mathrm{M}$. (E) Gel image of AF- $\mathrm{A}_{15}$ incubated with various concentrations of citrate $(\mathrm{pH} 7)$ for $24 \mathrm{~h}$ and then incubated with cisplatin for another $16 \mathrm{~h}$.

60 Different organelles inside a cell have different $\mathrm{pH}$ values. For example, endosomes and lysosomes are acidic and cancer tissues usually also have lower $\mathrm{pH} .{ }^{36}$ The $\mathrm{pH}$-dependent study is convenient to carry out with citrate since it can be used as a buffer over a wide $\mathrm{pH}$ range. Moderate DNA binding to 65 cisplatin was observed only at $\mathrm{pH} 3$ (Figure 3A), while binding was completely inhibited at higher $\mathrm{pH}$. This might be related to the protonation of citrate at $\mathrm{pH} 3$, thus suppressing its binding to cisplatin (the $p K_{\mathrm{a}}$ values of citrate are $3.14,4.75$ and 6.39). Overall, citrate is a strong inhibitor of cisplatin 70 binding to poly-A DNA over a wide $\mathrm{pH}$ range.

In addition to cisplatin, a few other Pt-based drugs have also been approved for clinical use such as oxaliplatin and carboplatin. Next we studied their reaction with DNA in citrate (Figure 3B). Interestingly, we only observed reaction 75 with cisplatin while no binding was detected with other $\mathrm{Pt}$ complexes in $16 \mathrm{~h}$. A moderate reaction with carboplatin was observed only after $48 \mathrm{~h}$ (Figure S3). The main difference between cisplatin and carboplatin or oxaliplatin is that the two chloride ligands are replaced by two chelating carboxyl 80 groups. The chloride leaving groups in cisplatin are liable compared to carboxyl leaving groups, which are moderately stable (Figure 3C). Therefore, cisplatin can be hydrolyzed and then react with citrate, while carboplatin or oxaliplatin does not react with citrate as readily. Mass spectrometry shows the 85 presence of both mono-coordinated and chelated products between citrate and cisplatin (Figure S4). 
The above studies mainly used $\mathrm{A}_{15}$ DNA since it forms discrete bands in gel while the $\mathrm{G}_{15}$ products smeared more. It needs to be noted that the inhibition effect is less significant for $\mathrm{G}_{15}$ (Figure S5). An important advantage of fluorescence 5 is multiplexed detection. With two different fluorophores, we next tested the effect of citrate in reaction selectivity between adenine and guanine. In the absence of citrate, both FAM-G $\mathrm{G}_{15}$ and $\mathrm{AF}-\mathrm{A}_{15}$ reacted and the mobility decreased with time (Figure $3 \mathrm{D}, \mathrm{E}, \mathrm{F}$ ). In the presence of citrate, AF-A 15 was 10 completely inhibited as expected (Figure $3 \mathrm{G}$ ), while FAM-G 15 still reacted (Figure $3 \mathrm{H}$ ), although slower than that in the absence of citrate. The merged band changed from orange to red after $4 \mathrm{~h}$ (Figure 3I), suggesting platination of FAM-G 15 . Therefore, an interesting effect of citrate is to increase the 15 selectivity of cisplatin towards guanine compared to adenine, which might have implications for guanine being the eventual target of cisplatin. ${ }^{37-39}$
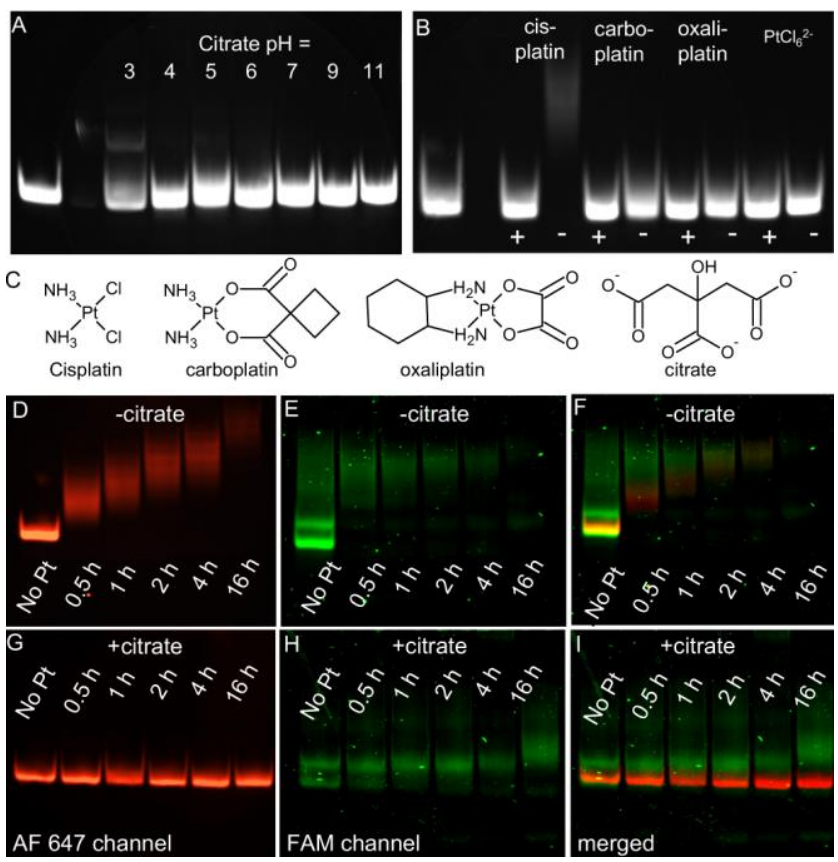

AF 647 channe

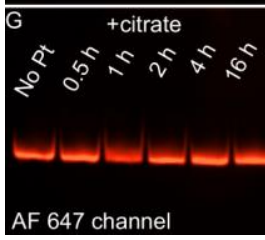

FAM channe

${ }_{0}$ Figure 3. (A) Inhibition of cisplatin binding to $A F-A_{15}$ as a function of $\mathrm{pH}$ in citrate. (B) Reaction of platinum-based compounds with $\mathrm{AF}-\mathrm{A}_{15}$ in the presence or absence of $10 \mathrm{mM}$ citrate (denoted by the ' + ' and '-' signs). For all the gels, the first lane on the left is the free DNA without cisplatin. (C) Structures of the platinum drugs and citrate. Mixture of AF$25 \mathrm{~A}_{15}$ and $F A M-G_{15}$ with cisplatin imaged with the AF channel (D, G), the FAM channel $(\mathrm{E}, \mathrm{H})$ and the merged $(\mathrm{F}, \mathrm{I})$ in the absence of citrate $(\mathrm{E}-\mathrm{F})$ or in the presence of $10 \mathrm{mM}$ citrate (G-I) as a function of time.

In summary, we employed fluorescently-labeled oligonucleotides for studying the reaction between cisplatin 30 and DNA. Important reaction information such as product distribution, kinetics, and stoichiometry can all be obtained with this simple method. We further showed that citrate is an inhibitor for this reaction but can increase selectivity toward guanine over adenine.

35 Funding for this work is from the University of Waterloo, the Canadian Foundation for Innovation, the Natural Sciences and Engineering Research Council (NSERC) of Canada and the Early Researcher Award from Ontario MRI.

\section{Notes and references}

$40{ }^{a}$ Department of Chemistry, Waterloo Institute for Nanotechnology, University of Waterloo, Waterloo, Ontario, N2L 3G1, Canada. Fax: 519 7460435; Tel: 5198884567 Ext. 38919; E-mail: liujw@uwaterloo.ca.

$\dagger$ Electronic Supplementary Information (ESI) available: [methods, additional gels, kinetics, mass spectrum]. See DOI: 10.1039/b000000x/ 45

1 Y. W. Jung and S. J. Lippard, Chem. Rev., 2007, 107, 1387.

2 T. Boulikas and M. Vougiouka, Oncol. Rep., 2003, 10, 1663.

3 X. Y. Wang and Z. J. Guo, Dalton T., 2008, 1521.

4 B. Rosenberg, L. Vancamp, J. E. Trosko and V. H. Mansour, Nature, 1969, 222, 385

5 D. Gibson, Dalton T., 2009, 0, 10681.

6 P. M. Takahara, A. C. Rosenzweig, C. A. Frederick and S. J. Lippard, Nature, 1995, 377, 649.

7 M. D. Hall, M. Okabe, D.-W. Shen, X.-J. Liang and M. M. 55 Gottesman, Annu.Rev.Pharmacol.Toxicol., 2008, 48, 495.

8 P. A. Andrews and S. B. Howell, Canc. Cell. Mon. Rev., 1990, 2, 35

9 Q. B. Lu, S. Kalantari and C. R. Wang, Mol. Pharmaceutics, 2007, 4, 624.

10 D. B. Zamble, D. Mu, J. T. Reardon, A. Sancar and S. J. Lippard, Biochemistry, 1996, 35, 10004.

11 A. Nemirovski, Y. Kasherman, Y. Tzaraf and D. Gibson, J. Med. Chem., 2007, 50, 5554

12 A. J. Zelazowski, J. S. Garvey and J. D. Hoeschele, Arch. Biochem. Biophys., 1984, 229, 246.

6513 C. Li, Z. Li, E. Sletten, F. Arnesano, M. Losacco, G. Natile and Y. Liu, Angew. Chem., Int. Ed., 2009, 48, 8497.

14 T. Ishikawa and F. Ali-Osman, J. Biol. Chem., 1993, 268, 20116.

15 M. Knipp, A. V. Karotki, S. Chesnov, G. Natile, P. J. Sadler, V. Brabec and M. Vasak, J. Med. Chem., 2007, 50, 4075.

7016 R. C. Todd, K. S. Lovejoy and S. J. Lippard, J. Am. Chem. Soc., 2007 129, 6370.

17 J. Reedijk, Chem. Rev., 1999, 99, 2499.

18 E. Segal and J.-B. Le Pecq, Cancer Res., 1985, 45, 492.

19 J.-S. Park, S. H. Kim, N.-K. Lee, K. J. Lee and S.-C. Hong, Phys. Chem. Chem. Phys., 2012, 14, 3128

20 A. Ciancetta, C. Coletti, A. Marrone and N. Re, Dalton T., 2012, 41, 12960.

21 R. S. Sorokanich, A. J. Di Pasqua, M. Geier and J. C. Dabrowiak, Chem. Biodivers, 2008, 5, 1540.

8022 W. Burgstaller, Microbiology, 2006, 152, 887.

23 J. Swiegers, I. Pretorius and F. Bauer, Curr. Genet., 2006, 50, 161.

24 D. E. Bauer, G. Hatzivassiliou, F. Zhao, C. Andreadis and C. B. Thompson, Oncogene, 2005, 24, 6314.

25 L. Costello and R. Franklin, Mol. Cancer, 2006, 5, 17.

8526 A. Usenik and M. Legisa, PLoS ONE, 2010, 5, e15447.

27 K. Cullen, Z. Yang, L. Schumaker and Z. Guo, J. Bioenerg. Biomembr., 2007, 39, 43.

28 S. F. Bellon and S. J. Lippard, Biophys. Chem., 1990, 35, 179.

29 F. Gonnet, F. Reeder, J. Â. Kozelka and J.-C. Chottard, Inorg. Chem., 1996, 35, 1653.

30 S. K. C. Elmroth and S. J. Lippard, J. Am. Chem. Soc., 1994, 116, 3633.

31 M. Treskes, J. D. Jong, O. R. Leeuwenkamp and W. J. F. Van Der Vijgh, J. Liq. Chromatogr. R. T., 1990, 13, 1321.

9532 T. Peleg-Shulman and D. Gibson, J. Am. Chem. Soc., 2001, 123 3171.

33 M. E. Bosch, A. J. R. Sanchez, F. S. Rojas and C. B. Ojeda, J. Pharmaceut. Biomed., 2008, 47, 451.

34 J. F. Hartwig and S. J. Lippard, J. Am. Chem. Soc., 1992, 114, 5646.

10035 E. R. Jamieson, M. P. Jacobson, C. M. Barnes, C. S. Chow and S. J. Lippard, J. Biol. Chem., 1999, 274, 12346.

36 I. Tannock, Cancer Metast. Rev., 2001, 20, 123

37 K. J. Barnham, M. I. Djuran, P. del Socorro Murdoch and P. J. Sadler, Journal of the Chemical Society, Chem. Commun., 1994, 0, 721.

10538 L. Rao and U. Bierbach, J. Am. Chem. Soc., 2007, 129, 15764.

39 M.-H. Baik, R. A. Friesner and S. J. Lippard, J. Am. Chem. Soc., 2003, 125, 14082. 